\title{
Author Correction: Uveal melanoma
}

Martine J. Jager, Carol L. Shields, Colleen M. Cebulla, Mohamed H. Abdel-Rahman, Hans E. Grossniklaus, Marc-Henri Stern, Richard D. Carvajal, Rubens N. Belfort, Renbing Jia, Jerry A. Shields and Bertil E. Damato

Correction to: Nature Reviews Disease Primers https://doi.org/10.1038/s41572-020-0158-0, published online 09 April 2020.

In the original version of this article, CXCL12 was misspelled as CXCR12 in the 'Mechanisms/pathophysiology' section. This error has now been corrected in the HTML and PDF versions of the article.

https://doi.org/10.1038/s41572-022-00339-9 | Published online: 17 January 2022

(c) Springer Nature Limited 2022 